This article has been published in:

Journal of Pragmatics 44.12 (2012) 1591-1606

Elsevier

http://dx.doi.org/10.1016/j.pragma.2012.04.002

If you want to quote from this document, please consult the page numbers in the right hand margins.

\title{
Ways of communicating emotional stance in online disagreements
}

\author{
Andreas Langlotz and Miriam A. Locher
}

\begin{abstract}
Online disagreements constitute a particularly interesting and relevant testing ground to explore different ways of communicating emotional stance (Mateosian, 2005). Our qualitative and quantitative analysis of 120 English postings from the MailOnline has revealed the notable presence of emotional stance through conceptual implication, explicit expression, and emotional description. While this quantitative survey can neither be regarded as comprehensive nor conclusive, we consider it as a first step towards detecting and categorizing different ways of expressing emotion in online and offline linguistic data. We suggest that a quantitative survey is complemented with a qualitative discussion to account for the complex and dynamic interaction between conceptual, relational and affective meaning. This speaks for a discursive approach for studying emotional stance in conflict and disagreements.
\end{abstract}

Keywords: Disagreement; Emotion; Relational work; Computer mediated communication

\section{Introduction}

Disagreements are grounded in the discrepant ideas, world views, goals, plans, and actions between two or more social agents (Smith and Mackie, 2000:503). Hence, whenever people engage with one another to interact and express their opinions, there is a latent but natural potential for disagreements to occur (Grimshaw, 1990:1). Previous research has shown that disagreements can be appraised in different ways from being supportive to highly oppositional 
(cf. Angouri and Locher, this issue). The focus in this paper is on the oppositional end of this cline. It studies conflictual disagreements (rather than supportive instances, cf. Sifianou, 2012; Angouri, 2012) and explores the relational and emotional dimensions of these speech events. We embed our analysis in the more general framework of 'relational work', i.e. the linguistic work that people invest in negotiating relationships (Locher and Watts, 2005). Through relational work, interactors can create relational meaning, i.e. they discursively construct and negotiate conceptualizations of their relationships. Along these lines, disagreements constitute particular speech events through which interlocutors judge the behavior of their communicative partner(s) in order to manage their social positions. Especially conflictual disagreements do not leave us cold; they arouse, more or less strongly, feelings of annoyance, irritation, anger, or contempt, and these are directed towards our communicative partner (Jones, 2001). Thus, we claim that conflictual disagreements are closely linked to negative emotional reactions, especially when one feels offended or treated rudely.

Emotions have been discussed with reference to face theory. Spencer-Oatey (2007) describes the connection between relational meaning and emotions as follows (see also Culpeper, 2010:60):

[F]ace is associated with affective sensitivity. Goffman (1967), Brown and Levinson $(1978,1987)$ and many other face theorists all agree that face is a vulnerable phenomenon, and hence associated with emotional reactions. Goffman (1967:6) explains it as follows: "If the encounter sustains an image of him that he has long taken for granted, he probably will have few feelings about the matter. If events establish a face for him that is better than he might have expected, he is likely to 'feel good'; if his ordinary expectations are not fulfilled, one expects that he will 'feel bad' or 'feel hurt'." (Spencer-Oatey, 2007:644, emphasis added)

This very close link between disagreement, face, and relational work can also be evidenced in a very distinct social practice and arena of language use (Clark, 1996:11) - the commentary sections of online newspapers. While not all newspapers may attract highly emotionalized or even offensive comments by their readers, we have chosen the MailOnline, a tabloid, because we expected less restraint in emotional expression and less moderator interference with conflictual statements (cf. Jucker, 1992, for stylistic differences in British newspapers; cf. also Neurauter, 2010; Upadhyay, 2010). The following examples are drawn from a sequence of comments that were posted between May 31 and June 02, 2010, in the MailOnline in reaction to an article with the title: "BP market plunge wipes billions off UK pension-funds, as shares in oil giant suffer fresh-falls":

(1) The US Senate should make the little island called the uk pay for this.

We should just impose our sanctions and will on BP. They need us more than we need them.

And the uk is a small island country.

- Matt, Arizona, USA, 31/5/2010 17:18

This statement receives the following comments:

(2) Matt, if we pulled out of Iraq, where exactly would that leave the USA? Oh yeah, up S@:*s creek. There may be more american soldiers out there, but there are pleant of British special 
op's out there clearing the way for the american soldiers. All so you yankies can have cheaper oil. Bit ironic really isn't it.

$[\ldots]$

- G, London, UK, 1/6/2010 21:01

(3) REPLY TO: G, London, UK, 01/6/2010 20:01

All i need to say to your pathetic comment is ...EVERYONE should be out of Afghanistan....and god forbid anything every happened in the UK...who'd be there to back you!?!? Oh...THE US!!!!!!!!!!!! And nature is going to be devestated by this horrible event and all you can do is whine and point fingers... why dont you stop typing and donate hair?? That wont cost your UK anything...selfish lot

- Alicia, USA, 1/6/2010 21:45

In examples (1)-(3) one can observe online disagreement and criticism that reflect face attack and escalation into an interpersonal conflict. The corresponding disagreements are strongly marked by different forms of emotional display, such as the use of negatively charged collocations ('little island' in (1)), the use of swearwords (S@:*s in (2)), or the use of capitalization and explanation marks to index emotional stance (!?!? Oh...THE US!!!!!!!!!!!! in (3)). Starting from our preliminary observations, we would therefore like to propose the following research questions:

-What is the interactional order of disagreements in the commentary section of our MailOnline data?

- What types of emotional display can we find in the MailOnline data?

-What is the link between emotional display, disagreement and relational work?

We will argue that the different strategies used to signal one's emotional state and the construal of such displays of emotion are decisive in understanding the quality of online disagreements as well as their potential relational effects. In support of this position we would like to propose a tentative descriptive framework for the classification and analysis of emotional display in online disagreements. Without any claims on comprehensiveness, this coding scheme will be discussed with reference to empirical data drawn from online disagreements.

To establish the theoretical foundations on disagreements and to discuss the role of emotions in construing them, we will proceed as follows. In section 2, we will provide the theoretical background to this study of disagreement and the connection to the interactional order and emotional dimensions. First, a definition of disagreements is given in terms of a conversation analytical framework for analyzing the initial turn-sequences of conflict talk. Rather than presenting the state-of-the-art in research on disagreements in detail, we attempt to sketch a working definition that reflects the interactive order of these speech events and which is therefore compatible with the discursive orientation of relational

work. In a next step, the fundamental role of emotions for sense-making is briefly sketched

and then related to our concrete object of analysis. In particular, we will outline the range of negative emotions that are associated with conflictual, face-attacking, disagreements. In section 2, we will refer to examples (1)-(3) in order to illustrate our theoretical definitions and 
considerations with naturally occurring linguistic behavior. On the basis of these theoretical foundations, we will then engage with the first two research questions - What types of emotional display can we find in the MailOnline data? / What is the link between emotional display, disagreement and relational work? - in section 3. Systematizing the different forms of emotional display in the 120 postings outlined above, we will propose a tentative framework for classifying and describing different strategies of indexing the posters' evaluative orientation in online disagreements. In section 4, we will discuss the link between emotional display, disagreement and relational work. The paper then concludes with suggestions for further research on the basis of our tentative and programmatic proposals.

\section{Disagreements: interactional order and emotional dimensions}

As discursive expressions of discrepant perceptions of ideas, goals, plans, and actions, disagreements are embedded within the broader social psychological context of conflict and conflict escalation:

Conflict is a disagreement between two or more parties who perceive incompatible goals or means of achieving those goals. The triggering event of a conflict can be perceived disagreements about scarce resources, methods of achieving a goal, the nature of a goal, or real or anticipated interference. (Jones, 2001:91)

With reference to Glasl (1992), Kempf (2003) proposes a scale of escalation to analyze the steps in a conflict-scenario, which range from cooperation (win-win), via competition (win-lose) and struggle (win-lose) to warfare (lose-lose). Every cooperative, win-win situation is characterized by the close alignment of the action-orientation of two (or more) social agents. In contrast, conflicts and disagreements emerge once either the actions/behavior of the other agent, the results of his/her actions, or the underlying goals for his/her behavior are perceived and emotionally appraised as being incompatible with one's own goals and actions as well as their desired results. Kempf (2003) claims that once such incompatibility is perceived and negatively evaluated, the behavior of the two social agents becomes competitive. When such competitions escalate into a confrontation, the transactional goals may become less important and the goal of the interaction becomes increasingly focused on the psychological (and physical) destruction of the other.

Two factors in this framework are important for an analysis of disagreements. First, when the conflict escalates, this is correlated with an increase in face attack. Second, we assume that this increase in face attack is correlated with an increase in negative emotions and their intensity. While this may lead to an increase of emotional display, people may also hide their actual states of emotional arousal to the communicative partner. We are, of course, aware that there are instances in which the mere fact that the act of disagreeing is possible may be perceived as positive and group enhancing rather than as negative (for an overview, see Sifianou in this special issue). However, in this paper we explicitly focus on disagreement that is perceived as negative and conflictual as suggested by the uptake of the interactants in the data. 


\subsection{Interactional order of disagreements}

From the perspective of interpersonal pragmatics (cf. Locher and Graham, 2010), the linguistic signaling and conversational management of disagreements and conflicts is of central importance. From these discourse-analytical perspectives disagreement and conflict not only constitute social-psychological states, but are bound to socially- normative discursive practices of conflictual engagement. In this sense, we fully agree with Vuchinich, who claims that:

Participants require a sense of "what we are doing here" in order to construct appropriate turns in talk. The speech activity in which participants are engaged is usually not overtly labelled. Participants rarely state "we are having a verbal conflict." Instead, assorted contextualization cues are used by participants to coordinate the speech activity [...]. During verbal conflict, participants have consensus on the speech activity they are engaged in. It takes two to tangle. But there is displayed a lack of consensus on some feature of the social world. The agreement on the speech activity makes it possible to continue interaction while the lack of consensus on other matters is addressed. (Vuchinich, 1990:119)

Arguing in the same vein, Muntigl and Turnbull (1998:226) approach the expression of disagreement in the opening sequences of conflict from the perspective of what they term "social psychological pragmatics". They therefore propose an elaborate conversation analytical scheme for classifying the conversational expression and the interactional order of disagreements that can then lead to more extended sequences of conflict talk (Grimshaw, 1990). Primarily focusing on dyadic arguments between two interlocutors $A$ and $B$, they suggest that disagreements and conflict openings - termed

Table 1. Types of T2/T3 disagreements (after Muntigl and Turnbull, 1998), examples by the authors.

\begin{tabular}{|c|c|c|}
\hline \multirow[t]{2}{*}{ Type of disagreement } & \multicolumn{2}{|c|}{ T1 (claim by A): the UK is a small island country } \\
\hline & T2 (reaction by $\mathrm{B}$ ) & T3 (counter-reaction by A) \\
\hline $\begin{array}{l}\text { Irrelevancy claim (IR): "previous claim is not relevant } \\
\text { to the discussion at hand" (229) }\end{array}$ & So what? & $\begin{array}{l}\text { What a stupid remark, } \\
\text { it is obvious! }\end{array}$ \\
\hline $\begin{array}{l}\text { Challenge }(\mathrm{CH}) \text { : "a speaker questions an addressee's } \\
\text { prior claim and demands that addressee provide } \\
\text { evidence for his/her claim, while suggesting that } \\
\text { the addressee cannot do so" }(230)\end{array}$ & What do you know about it? & $\begin{array}{l}\text { I know much more about } \\
\text { it than you. }\end{array}$ \\
\hline $\begin{array}{l}\text { Contradiction (CT): "a speaker contradicts by uttering } \\
\text { the negated proposition expressed by the previous } \\
\text { claim" (231) }\end{array}$ & Hey, it is Great Britain. & I do not consider it great at all. \\
\hline $\begin{array}{l}\text { Counterclaim (CC): "speakers propose an alternative } \\
\text { claim that does not directly contradict nor } \\
\text { challenge other's claim" (231) }\end{array}$ & $\begin{array}{l}\text { It might be small but it is politically } \\
\text { important. }\end{array}$ & $\begin{array}{l}\text { No, it has lost its global political } \\
\text { influence after WW2. }\end{array}$ \\
\hline Act combinations (frequently CT and CC) & $\begin{array}{l}\text { This is wrong; the UK is less indebted } \\
\text { than the US and therefore bigger, } \\
\text { economically speaking. }\end{array}$ & $\begin{array}{l}\text { Well, I don't think so, check the } \\
\text { latest stats. }\end{array}$ \\
\hline
\end{tabular}

"arguing exchanges" (Muntigl and Turnbull, 1998:227) - follow a tripartite turn-structure (T1T3) with the conversational setup reflected below: 
T1: claim by speaker $A$

T2: speaker B disputes claim in T1

T3: speaker A disagrees with B by supporting the original claim in T1 or by directly contesting B's disagreement

(see Muntigl and Turnbull, 1998:227)

According to Muntigl and Turnbull (1998:228-236), the disagreements in T2 and T3 can come in the form of five types presented in Table 1: irrelevancy claims, challenges, contradictions, and counterclaims and the combination of contradictions plus counterclaims. The distinction between these categories is established on a content level. We are using constructed responses to fill the T2 and T3 slots - in reaction to the statement "the uk is a small island country", example (1) regarded as constituting T1, to illustrate these alternative types.

This scheme of different subtypes of speech acts, used to implement express disagreement between two conversational partners and thus to initiate a conflict, implies differences in their aggressive potential. Quoting Labov and Fanshel (1977), Muntigl and Turnbull argue that in terms of their potential negative impact on the face of the communicative partner, these types of disagreement show different degrees of gravity:

According to Labov and Fanshel (1977:58-59), conversational actions with the greatest social impact are "not such speech acts as requests and assertions, but rather challenges, defenses, and retreats, which have to do with the status of the participants, their rights and obligations, and their changing relationships in terms of social organization". (Muntigl and Turnbull, 1998:242)

They therefore propose that the types of disagreements can be ranked as follows with regard to their aggressive potential (1998:242-252): While irrelevancy claims and challenges are the most aggravating ones, contradictions, act combinations and counterclaims are more argumentative and thus more closely focused on solving the disagreement. (It is important to note that the linguistic realization is not predicted by this ranking of potential face-aggravation: to what extent mitigation co-occurs with the types of responses may vary.) An irrelevancy claim constitutes pure opposition that limits any further discussion because it attacks the fundamental social skill of making relevant claims. This form of disagreement is reflected in (3); when Alicia states: All i need to say to your pathetic comment is ... she meta-communicatively disqualifies G's posting as being irrelevant. Moreover, she directly challenges him by writing: why dont you stop typing and donate hair?? That wont cost your UK anything...selfish lot. Another challenge is contained at the end of (2) when $G$ directly attacks the supposedly oilgreedy Americans, obviously including Matt: All so you yankies can have cheaper oil. Thus, challenges are produced in an aggressive manner as they implicate that the interlocutor cannot back up his/her claims; they attack the knowledge and competency of the other. By contrast, although they constitute a direct and unambiguous rejection of the other's claim, contradictions are not as aggressive because they do not directly attack the rationality, competency, or knowledge of other. In (1)-(3), we cannot detect any contradiction that negates Matt's original claims explicitly but the postings are centered about a number of counterclaims. Counterclaims such as There may be 
more american soldiers out there, but there are pleant of British special op's out there clearing the way for the american soldiers in (2) constitute the most argumentative form of disagreement. By providing an alternative claim and by making more explicit why the speaker disagrees, counterclaims invite an interactional negotiation of the disagreement. Thus, instead of confronting the communicative partner with a me against you tactic, it does not centrally attack the other's self- image and so delays and mitigates explicit disagreement.

While Muntigl and Turnbull's framework offers a very good starting point for systematizing the discursive structure of conflictual disagreement, arguing, and potential conflict, it is necessary to point to and scrutinize some discrepancies between their CA framework and our written posts from the MailOnline commentaries section to be used as data in our paper. These discrepancies involve the integration/conflation of different communicative acts in the posts as well as the particular participation framework of the newspaper commentary section. For these reasons, we will return to the interactional framework of disagreements in light of our corpus in section 3.

\subsection{Emotional dimensions of conflict and disagreements}

Schwarz-Friesel (2007) describes emotions as dynamic syndrome complexes (see Fig. 1). A compatible view is also adopted by Russell (1991, quoted in Culpeper, 2010:57). The corresponding emotional cycle can be illustrated as follows: (1) our emotions are started as the receptive state to some internal (proprioceptive) or external stimulus, (2) this first reception leads to a somatic or body state, (3) which makes it possible for us to perceive the emotion as a feeling or psychic state. (4) This psychic state is associated with an evaluation (good vs. bad), (5) that can then be expressed communicatively and (6) thus be perceived by another person. So importantly, only external stimuli and the expressive responses to those stimuli can be observed from a discourse analytical perspective. This is what you find in the box with the broken line.

While emotions have not received a great deal of attention in linguistics and pragmatics (for exceptions see, e.g., Ochs and Schieffelin, 1989; Fiehler, 2002; Pepin, 2008; Locher and Langlotz, 2008; Wilce, 2009), their role has received more attention in the field of communication, in particular conflict communication research. Nevertheless, Guerrero and La Valley (2006:69) also state in their overview article: "Surprisingly, [...], communication researchers have rarely investigated the connection between emotion and behaviour in conflict interaction". By proposing such a strong association between emotions, disagreements, conflict, and relational work in this paper, we follow Jones (2001), who claims that events that cause conflict are events that elicit emotion. She further argues that the emotional definition of the conflict affects the strategic orientation of the communicators. Most crucially, with regard to our research questions, she proposes that emotional intensity is linked to our perceptual processes in conflict interpretation. For conflictual online disagreements this would imply that the strength of a given disagreement should be signaled by correspondingly intensive emotional cues with emotional communication being a source for contagion. Thus, according to Jones, emotional communication frames conflicts by 
revealing the moral orientation of the interactors. In addition, with regard to the relational dimensions of disagreement and conflict, emotional communication is strongly associated with identity in interpersonal and intergroup conflict. Recall that this view is shared by SpencerOatey (2007) in her face-based account of affective meaning in interpersonal engagement. Along these lines, we claim that the different types of disagreement outlined above must be emotionally loaded both in terms of their potentially aggressive and face-threatening nature as well as in terms of their power to trigger negative emotional evaluations.

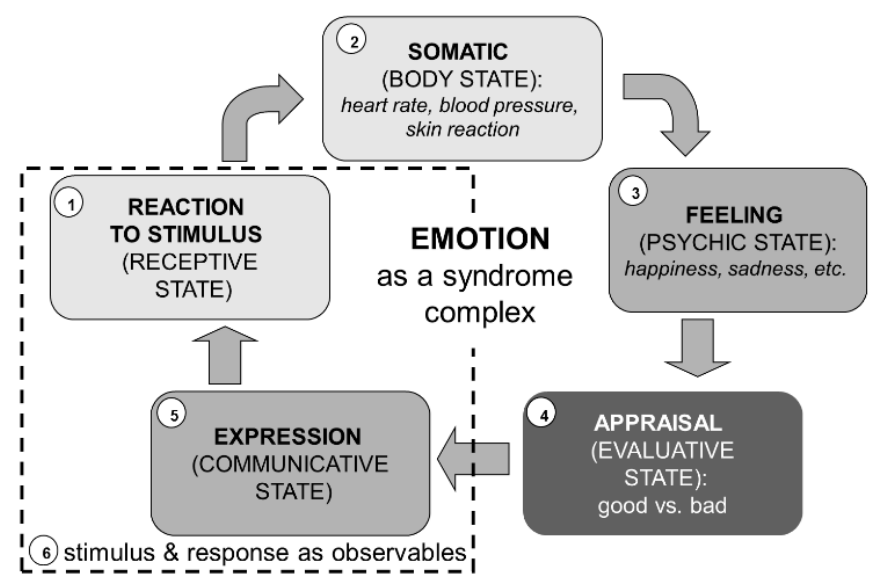

Fig. 1. The dynamic syndrome complexes of emotional cycles (Schwarz-Friesel, 2007:46).

Table 2. The emotion and its intensity range according to Guerrero and La Valley (2006).

\begin{tabular}{|c|c|c|c|}
\hline $\begin{array}{l}\text { Emotion and } \\
\text { intensity range }\end{array}$ & Associated subtypes & Causes in conflict & $\begin{array}{l}\text { Reactions: action tendency in } \\
\text { communication }\end{array}$ \\
\hline $\begin{array}{l}\text { Anger } \\
\text { annoyance } \rightarrow \text { rage }\end{array}$ & $\begin{array}{l}\text { Annoyance, irritation, } \\
\text { contempt, exasperation, } \\
\text { rage }\end{array}$ & $\begin{array}{l}\text { Face-attack, aggression, threat, } \\
\text { or physical harm } \\
\text { frustrating situations } \\
\text { unfairness and inequity } \\
\text { incompetent behavior }\end{array}$ & $\begin{array}{l}\text { Counter-attacks } \\
\text { disapproval }\end{array}$ \\
\hline $\begin{array}{l}\text { Hurt } \\
\text { irritation } \rightarrow \text { agony }\end{array}$ & $\begin{array}{l}\text { Agony, anguish, } \\
\text { sadness, suffering }\end{array}$ & $\begin{array}{l}\text { Accusations and threats } \\
\text { negative evaluations } \\
\text { lies } \\
\text { jokes (irony, sarcasm) }\end{array}$ & $\begin{array}{l}\text { Counter-attacks for self- } \\
\text { defence } \\
\text { acquiescent responses } \\
\text { (crying, conceding, } \\
\text { apologizing) } \\
\text { invulnerable responses } \\
\text { (ignoring the problem) }\end{array}$ \\
\hline Guilt & $\begin{array}{l}\text { Shame, } \\
\text { embarrassment, } \\
\text { regret }\end{array}$ & $\begin{array}{l}\text { Relational/role obligation } \\
\text { normative standards } \\
\text { pointing to sacrifices } \\
\text { making comparisons with } \\
\text { others }\end{array}$ & $\begin{array}{l}\text { Apologizing and conceding } \\
\text { guilt } \\
\text { justify behavior } \\
\text { trying to appease the other } \\
\text { refusals and avoidance }\end{array}$ \\
\hline
\end{tabular}

Guerrero and La Valley (2006) discuss anger, hurt (sadness), and guilt as conflict-related emotions with corresponding degrees of intensity, causes and likely reactions, as the overview presented in Table 2 shows. ${ }^{1}$

\footnotetext{
${ }^{1}$ Guerrero and La Valley (2006) also identify jealousy as a conflict-related emotion. However, they primarily discuss research from the context of marriage-counseling, which is not of direct interest to our study.
} 
In a similar vein, Culpeper claims with a focus on impoliteness:

Displaying emotions such as contempt or anger has nothing in itself to do with impoliteness. However, somebody displaying great contempt for and anger at someone and doing so publicly may be judged (...) to have acted in an inappropriately and unfairly hurtful way (...), causing an emotional reaction such as embarrassment or anger (...). (Culpeper, 2010:60)

Haidt (2003:855) calls such emotions 'moral' emotions. Moreover, he proposes the more finegrained distinction between negatively valenced 'other-condemning' moral emotions (including anger, disgust, and contempt) and negatively 'self- conscious' moral emotions (embarrassment, shame and guilt) (Culpeper, 2010:61). Using report data on the judgments of impoliteness by informants, Culpeper finds a slight tendency for the former category to be rather associated with violations of sociality rights, whereas the latter is more oriented towards face-violations (2010:62-65). These insights are relevant for the present study because they indirectly support our claim that conflictual online disagreements in our data can be associated with negative emotions and corresponding variants of emotional display.

When relating Culpeper's ideas and Guerrero and La Valley's schema of emotions to the conflict in examples (1)-(3), we see that the first comment by Matt can be classified as a challenge. It threatens BP by suggesting that they should pay for the damage caused by the oil leakage. In addition he drives a face-attack at the UK (and its citizens). More specifically, the statement "And the uk is a small island country" alludes to a distancing and face-threatening social relationship. Matt construes the American WE as being bigger, greater and better, while the YOU - the UK - is portrayed as being small and unimportant. In other words, Matt here performs a symbolic act of self-empowerment. This implies an underlying emotional evaluation of contempt against UK citizens - an other-condemning emotion in Culpeper's terms. This competitive scenario is, however, not marked by explicit emotional display, rather these emotions are alluded to through the conceptualization of the UK as a minor and insignificant state. By triggering this conceptual implication, his claim is likely to arouse anger.

Indeed $G$ seems to be annoyed with Matt in (2). In his extract we can now find explicit emotional display. We would like to claim that $\mathrm{G}$ first challenges Matt's conceptualization of the UK as being insignificant by producing a counter-argument in the form of a rhetorical question which implies WE cannot be small. However, this question is followed by explicit emotional display in terms of an exclamation oh yeah which alludes to the irrelevance and absurdity of Matt's claim as well as the metaphorical conceptualization up shit creek with corresponding negative associations. Here, G clearly intensifies the display of his annoyance beyond the level of an argumentative debate. He thus recontextualizes his previous rhetorical questions as an angry and annoyed counter-challenge. Clearly, this has an aggravating impact on Matt's face. This social and emotional aggravation becomes very clear in his further comment All so you yankies can have cheaper oil. The direct name-calling gesture you yankies is an overt and intensive display of annoyance and contempt and thus frames 


\begin{tabular}{|c|c|c|c|c|c|c|}
\hline & Title of article & $\begin{array}{l}\text { Number of } \\
\text { posts }\end{array}$ & $\begin{array}{l}\text { Number of } \\
\text { contributors }\end{array}$ & $\begin{array}{l}\text { Number of } \\
\text { words }\end{array}$ & $\begin{array}{l}\text { Average } \\
\text { per post }\end{array}$ & $\begin{array}{l}\text { Standard } \\
\text { deviation }\end{array}$ \\
\hline 1 & $\begin{array}{l}\text { Fury after woman who falsely cried rape is } \\
\text { handed an } £ 80 \text { fixed penalty }\end{array}$ & 20 & 19 & 1319 & 66 & 43 \\
\hline 2 & $\begin{array}{l}\text { 'Census police' will chase up late form fillers in } \\
\text { operation costing hundreds of millions of } \\
\text { pounds }\end{array}$ & 20 & 19 & 914 & 46 & 45 \\
\hline 3 & $\begin{array}{l}\text { BBC to be 'more sceptical' of the royals after } \\
\text { republicans complain about 'fawning' wedding } \\
\text { coverage }\end{array}$ & 20 & 20 & 1103 & 55 & 37 \\
\hline 4 & $\begin{array}{l}\text { Stricken nuclear plant's No. } 3 \text { reactor 'may have } \\
\text { cracked' as Fukushima. Fifty workers are } \\
\text { treated for radiation contamination }\end{array}$ & 20 & 20 & 1100 & 55 & 48 \\
\hline 5 & $\begin{array}{l}\text { 'Can I have your autograph, miss? I saw you in } \\
\text { a porn film'... School worker suspended after } \\
\text { secret life exposed by student }\end{array}$ & 20 & 20 & 995 & 50 & 43 \\
\hline \multirow[t]{2}{*}{6} & $\begin{array}{l}\text { BP market plunge wipes billions off UK pension } \\
\text { funds as shares in oil giant suffer fresh falls }\end{array}$ & 20 & 20 & 1038 & 52 & 37 \\
\hline & Total & 120 & 118 & 6469 & 54 & 42 \\
\hline
\end{tabular}

G's disagreement as a face attack. His annoyance is in line with Guerrero and La Valley's scheme in that his reaction expresses his disapproval and produces a counter-attack.

In (3), this attack is again taken up by Alicia who also displays a negative emotional orientation to the previous post in her use of language. She indicates this stance when she reacts in the form of another aggressive counter attack at $\mathrm{G}$. She seems to further raise the level of emotional contagion by expressing her rage. What is striking here is the massive increase in explicit and very intensive emotional display and the fact that the conceptual content on which the argumentation is based moves to the background. Alicia clearly evaluates G's previous statement in the form of a metacomment by means of which she expresses her anger at him: "All i need to say to your pathetic comment is ...." Also, she ascribes weak emotions and selfishness to G ("all you can do is whine and point fingers") and calls him and his compatriots a "selfish lot". Alicia thus leaves the argumentative grounds of disagreement (the conceptual content is in the background) for the sake of highlighting her challenges to G's positive face and her attempts at weakening and destroying it. Her posting thus contains strong emotional signals with the potential intention to trigger guilt, shame and embarrassment in $\mathrm{G}$. Following Culpeper's categories introduced above, $\mathrm{G}$ is meant to become self-conscious of his social transgression and this results in loss of positive face.

The data also suggest that we can link our linguistic analysis to the escalation scale offered by social psychology (Kempf, 2003). The move from cooperation, to competition, and confrontation indeed seems to be associated with a corresponding shift away from argumentative conceptualizations towards forms of displaying disagreements which are clearly centered on face aggravation and increasingly negative and intense emotional display. But how can we analyze the links in terms of interpersonal pragmatics? In what follows, we would like to sketch a preliminary framework for the analysis of emotional display in online disagreements by looking at data gathered from online newspaper commentaries. 


\section{A tentative framework for the analysis of signaling emotions in online disagreements}

Our data for the empirical snapshot of how emotional stance is indexed in commentaries on online newspaper articles in English is taken from the archive of the open access Mail Online (http://www.dailymail.co.uk), the UK online version of the Daily Mail and The Mail. As this site is part of the public domain, we consider it ethically acceptable to use the data for our analysis (cf. Ess \& the AolR ethics working committee, 2002:5). There is an invitation for readers to comment on articles posted on this site during three days after the publication of the article. After this period, the platform is closed. According to the site, the "comments ... have been moderated in advance". In addition, the site is careful to point out that the "views expressed in the contents above are those of our users and do not necessarily reflect the views of MailOnline." For our analysis, we have randomly chosen six topics that promised to be emotionally discussed by commentators: (1) false rape allegations, (2) census policy, (3) the Royal Wedding, (4) the stricken Japanese nuclear plant, (5) a person who worked at a school and was also an adult movie actress, and (6) the BP market plunge. Article 6 was first published in 2010, while all other articles were published on 25 March 2011. ${ }^{2}$ From the comments archive for each article we included the first 20 posts in our corpus. Table 3 shows that a post had 54 words on average but could range from one word only to

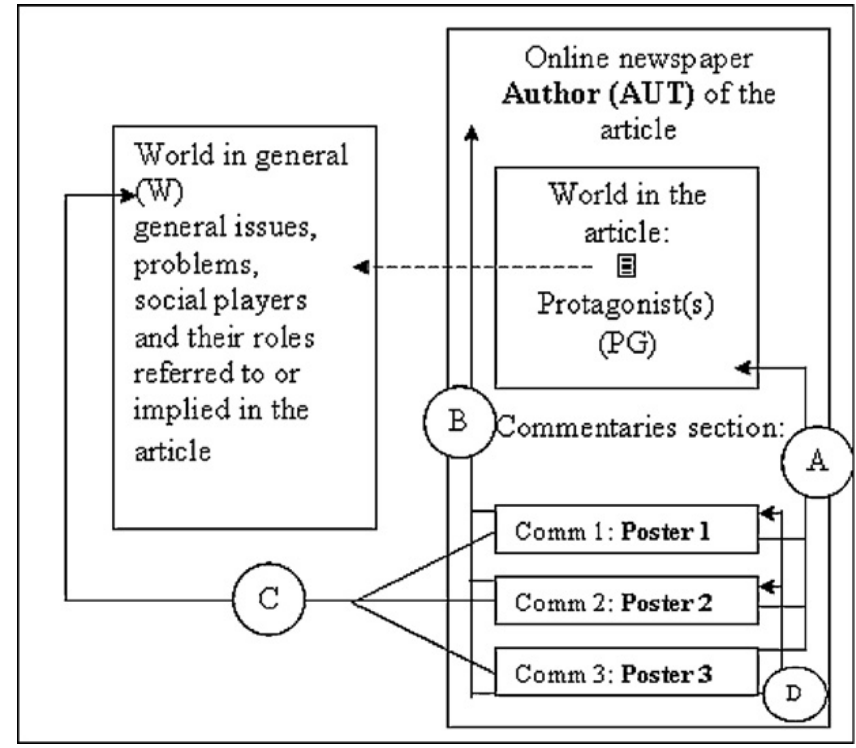

Fig. 2. The participant framework of the online commentary section.

186. While a system quoting function was not available to the commentators, there are 10 cases where posters copy paste comments from previous contributions and in 26 cases overall we can establish a coherence link to a previous post rather than to the article itself (see below). In what follows, we will first discuss the interactional order of our data and its impact on disagreements before moving to the emotional display in the identified disagreements.

\footnotetext{
${ }^{2}$ We presented our analysis of the 2010 article at the Politeness and Impoliteness Online and Offline conference in June 2010 and later enlarged our corpus.
} 


\subsection{Interactional order of our data}

The analyzer has to be careful when applying Muntigl and Turnbull's CA framework to CMC data although their classification of T2 and T3 provides a sophisticated and useful framework to scrutinize disagreements and conflicts as a socially-distributed discursive practice. In order to understand the dynamics of disagreements in our data, we had to adapt our analytical categories and take the different, complex interactional order of the MailOnline platform into account. The disagreements uttered in an online newspaper discussion forum are not merely directed against the interactional partner as in Muntigl and Turnbull's dyadic model. Rather, they can make different social agents the butt of criticism. These targets for disagreement are sketched in Fig. 2.

As indicated by the bold arrows (A-D) in Fig. 2, a commentator has alternative social targets towards which he/she can direct his/her disagreement. ${ }^{3} \mathrm{He} /$ she can refer to the protagonist(s) in the world of the article (A) or address it to the author (B). Moreover, a post can point to affairs relating to the world in general that are triggered through the article's content (C) - this is indicated by the dashed arrow. Finally, the commentator may aim his/her contribution at another poster (D). This complex 'participant' framework for online commentaries is also reflected in examples (1)-(3). In (1) Matt directs his accusation at BP, which constitutes a protagonist in the article. Moreover, he highlights the UK as a social player in the world. Being a British company, the link between PG and W is obvious. (1) thus covers the butts $A$ and $C$ in the figure. As evidenced by the personal address, $G$ 's reaction in (2) is more clearly targeted at Matt. Implementing the butt- type $D$, his disagreement is more conversational in that it is directly addressed to an interactional partner in the commentaries section. However, he also takes up Matt's more general aggression against the UK and counters the offence against it by highlighting the military dependency of the US on British soldiers. As Matt's derogation of the UK, this criticism is grounded in $\mathrm{W}$ and implies $\mathrm{C}$ as another butt of G's posting. The same is true for Alicia's aggressive reaction in (3); she clearly disagrees with $G$, but further expresses her criticism of the Anglo-American engagement in Afghanistan as well as the oil catastrophe.

It is important to highlight that it is not always possible to clearly delimit the butt of disagreement in a given online posting. While first name addresses and quotes as in (2) and (3) convey explicit references to previous posts and posters, respectively, disagreements are often posted as part of a coherent strand of negative comments on the issue portrayed by

Table 4. The general argumentative contribution of the 120 turns (double counting allowed).

\begin{tabular}{lrrrrrrrr}
\hline Function & Total & $\%$ & $\begin{array}{r}\text { False } \\
\text { Rape }\end{array}$ & $\begin{array}{r}\text { Census } \\
\text { Police }\end{array}$ & $\begin{array}{r}\text { Royal } \\
\text { Wedding }\end{array}$ & $\begin{array}{r}\text { Stricken } \\
\text { Nuclear Plant }\end{array}$ & $\begin{array}{r}\text { Adult movie } \\
\text { teacher }\end{array}$ & $\begin{array}{r}\text { BP market } \\
\text { plunge }\end{array}$ \\
\hline Disagreement & 104 & 69 & 20 & 18 & 19 & 13 & 16 & 19 \\
Extension & 28 & 19 & 5 & 2 & 7 & 7 & 2 & 6 \\
Agreement & 19 & 13 & 0 & 4 & 1 & 4 & 10 & 0 \\
Total & 151 & 101 & 25 & 23 & 27 & 24 & 27 & 25 \\
\hline
\end{tabular}

\footnotetext{
${ }^{3}$ According to the MailOnline site, inappropriate commentaries can be subject to removal when reported. This interference with expressing an opinion could also be a potential butt of disagreement. We have not included this aspect in our framework because the interactors never refer to a potential moderator in our data.
} 
Table 5. The participation framework of the MailOnline corpus (120 posts, double labeling possible).

\begin{tabular}{|c|c|c|c|c|c|c|c|c|}
\hline Function & Total & $\%$ & $\begin{array}{l}\text { False } \\
\text { Rape }\end{array}$ & $\begin{array}{l}\text { Census } \\
\text { Police }\end{array}$ & $\begin{array}{l}\text { Royal } \\
\text { Wedding }\end{array}$ & $\begin{array}{l}\text { Stricken } \\
\text { Nuclear Plant }\end{array}$ & $\begin{array}{l}\text { Adult movie } \\
\text { teacher }\end{array}$ & $\begin{array}{l}\text { BP market } \\
\text { plunge }\end{array}$ \\
\hline $\begin{array}{c}\text { A: Reference to protagonist / } \\
\text { world in the article }\end{array}$ & 88 & 51 & 13 & 17 & 17 & 11 & 17 & 13 \\
\hline B: Reference to author & 5 & 3 & 0 & 0 & 0 & 4 & 0 & 1 \\
\hline C: Reference to outside world & 59 & 34 & 14 & 11 & 9 & 8 & 6 & 11 \\
\hline $\begin{array}{l}\text { D: Reference to a previously } \\
\text { posted comment }\end{array}$ & 22 & 13 & 1 & 3 & 0 & 3 & 7 & 8 \\
\hline Total & 174 & 101 & 28 & 31 & 26 & 26 & 30 & 33 \\
\hline
\end{tabular}

a given article. However, the absence of clear-cut references makes it very difficult for the analysts to determine whether such comments are related to $A$ or $C$ or whether they engage with the comment of another poster without marking this explicitly. As a result, it is difficult for the researcher to always assign disagreements or agreements to prior postings in the commentaries section. For this reason we follow Bolander (2012) and Baym (1996:325) who insist on an explicit link to a previous post or position in order to establish agreement and disagreement.

We decided to analyze the 120 comments on the six newspaper articles in our corpus in two steps: first we looked at the overall argumentative thrust of the posts and then classified the contributions according to their participation framework (A-D). The argumentative contributions of the posts were classified into three general categories: agreement, disagreement and extension. The first two categories were established by taking into account the general gist of the post in that we asked whether the contributor voiced agreement or disagreement with the newspaper article or a previously posted contribution. Expressing agreement with one aspect or one previously posted comment might imply disagreement with another position previously raised (cf. Baym, 1996; Bolander, 2012). This means that potentially many posts could be categorized as both agreement and disagreement at the same time. Our methodological decision was to allow this double labeling only when an explicit link was made to a prior post by the commentator him- or herself. For example, when a disagreement on one aspect only implicitly contained an agreement with a previously voiced opinion, the post was only categorized as disagreement. The third category 'extension' refers to those posts that, while being related to the topic as such, do not support or contradict a position previously voiced in the article or the comments. Both authors rated independently and achieved a reliability rating of $85 \%$. The 18 cases of different categorization were resolved after discussion.

We can see in Table 4 that disagreement occurred in 104 of the 120 comments. This means that this category is the most dominant with $69 \%$. In only $13 \%$ of the posts ( $n=18$ ) could we find an explicit agreement expressed, while category 'extension' made up $19 \%(n=28) .{ }^{4}$ The row of totals gives us an indication of how much double labeling occurred within an article and it also indicated which articles triggered more diverse positions. In addition (and not displayed in Table 4), we established that only 6 posts contained extension exclusively, 11 posts featured

\footnotetext{
${ }^{4}$ There were no contributions off topic.
} 
agreement on its own, and 76 posts were made up of disagreement alone. The combinations were 'agreement + disagreement' in 7 instances, 'agreement + extension' in 1 case, 'disagreement + extension' in 22 occurrences. Overall, we can thus claim that our corpus distinguishes itself through a clearly critical stance.

In order to follow up on the interactional frame described in Fig. 2, we established next who the target of the argumentative contributions were. Table 5 displays the participation framework A-D. The most frequent target of the comments was a protagonist or an issue from the article itself (51\%; 88 comments). This might be explained by the fact that the default display of the commentaries always lists the most recent on top of the list so that the closest position on

screen for a comment is indeed the article itself rather than a previously published post that moves down the list over time. In only 5 instances was the author of the article the target of the always critical posts. This shows that, in our corpus, the points of contention were the facts and stories reported on rather than the author of the texts and his or her quality as a reporter. This is in contrast to Neurauter's (2010) findings, who reported that many of the ad hominem attacks that she investigated in a corpus of online comments to British newspaper articles were indeed addressed to the journalist. In 59 comments (34\%) the butt of the comment referred to the outside world in our corpus. The posters thus draw on their knowledge of the topic and refer to actors, facts, positions not raised or elaborated on in the article. Finally, only 22 comments (13\%) contained an explicit link to a previously published comment. The picture we thus get from our small corpus is that the primary target is the state of affairs portrayed in the article and that the interactive possibilities that the platform offers are not exploited equally. Having established this practice, it is time to return to the role of the display of emotions in disagreements.

\subsection{Emotional display in disagreements}

In face-to-face disagreements, emotions can be displayed in the following ways: They can be expressed non-verbally or prosodically through facial expression, gestures, intonation; through bodily symptoms such as sweat, blush, turning pale, pupil dilation or verbally through interjections, emotion words, expressive speech acts, etc. Emotions can also be described through explicit representations or meta-comments. All of these cues may index emotions. By using the term 'index', we follow Ochs's (1992) notion of indexicality, which assumes that complex psychological categories such as gender cannot be directly encoded in language but rather depend on an array of indexes that point to them. We assume that from a linguistic perspective, the signaling of emotional stance is equally complex and depends on the indexical power of a variety of forms of emotional display. As mentioned in section 3.1, only the expressive stage and to a certain extent the observable physical change in the body states just mentioned allow the researcher to discuss emotional indexing. In other words, while emotions are argued to play a crucial part in interaction per se, as researchers we can only rely on its explicit display for analysis. In the case of newspaper commentaries on articles in a computermediated environment, we have to rely entirely on language in our analysis since we do not 
have access to physical, visual cues. This, however, is not only the fate of the analyst, but crucially also that of the online interactants themselves, suggesting that our attention to written emotional display is justified. After having discussed examples (1)-(3) from different angles, we will now proceed to a systematic study of the ways in which emotions are indexed in the 120 commentaries of our Mail Online corpus.

Schwarz-Friesel (2007:Ch. 5) suggests a two-partite distinction of means of expressing emotions: (1) verbal expression and visual intensification, and (2) verbal descriptions and metacomments. In our analysis, we took these categories as a starting point, but decided to distinguish between the direct expression of emotions, the implied indexing of emotional stance by means of implicature, 5 and finally the description of emotions. Table 6 shows the new categorization and an example for each sub-category from our corpus. It thus presents an overview of alternative forms of expressing emotions verbally and different ways of visual intensification. So, for example, emotions could be expressed by verbalizing an emotional reaction such as laughter rendered as 'HAHAHA' or the use of intensification such as capitalization and expressive use of punctuation marks (THE US!!!!!!!!!!!!) or lengthening (ooooooooops!...). Emotions could be implied by the use of conceptual implicature (for you to have a proper education) and the scope of lexical connotation (creep back into your little marxist hole), as well as the use of sarcasm, irony, and wordplay. Finally, emotions could be described by the use of emotion words such as 'horrible' or 'disgusting' and verbal descriptions/ascriptions of emotional states (all you can do is whine and point fingers). Of course, the style of such descriptions influences the perception of their emotional qualities.

Table 7 shows that, overall, we were able to tag the three general emotional display categories of implying, expressing and describing 309 times in our 120 online posts. The majority of these ( $n=176,57 \%$ ) were accessible by means of implicature, followed by emotional expression ( $n=101,33 \%$ ) and description ( $n=32,10 \%)$. The text on the Royal Wedding (21\%) triggered most emotional cues, followed by the BP market plunge (17\%), with the Stricken Nuclear Plant last (13\%). It should be pointed out that, while the occurrence of different strategies within a post is possible, the numbers indicate the presence or absence of a strategy within a post and do not further quantify the number of times a strategy is used within a comment.

The next step is to see what types of emotional indexing occurred in the three argumentative moves identified for the practice in the corpus (disagreement, agreement, extension). Given the fact that $69 \%$ (104 posts) of our corpus contain disagreement, we added a normalized figure after each column to indicate the relative frequency of the strategy within the 
Table 6. Linguistic and graphic means for indexing emotional display.

\begin{tabular}{|c|c|}
\hline & Examples from our corpus \\
\hline \multicolumn{2}{|l|}{ Expression } \\
\hline Exclamations & who'd be there to back you!?!?/what a sillyapproach \\
\hline Intensification & BI***** BRITS/EVERYONE/THE US!!!!!!!!!!!!!//ooooooooops!.... \\
\hline Name calling & You yankies/selfish lot \\
\hline Verbalization of emotional reaction & НАНАНАНАНАНАНАН \\
\hline Smileys & They gotta catch me first :) \\
\hline Interjections & oh, oh yeah \\
\hline Emotional construction & these people/these republicans \\
\hline \multicolumn{2}{|l|}{ Implication } \\
\hline Conceptual implications & for you to have a proper education/friendly fire scenario \\
\hline Lexical connotations & creep back into your little marxist hole \\
\hline Metaphors and their stylistic implications & ups@:*screek \\
\hline Sarcasm & $\begin{array}{l}\text { It says she's a clerical assistant, not a teacher. Read the article } \\
\text { perhaps, before commenting }\end{array}$ \\
\hline Irony & $\begin{array}{l}\text { I have several movies, Botham's Ashes and the first season of } \\
\text { the Waltons ready to watch on the great day. I haven't } \\
\text { watched Charlie and Di's wedding yet. }\end{array}$ \\
\hline Word play & Der Stasi vill soon be amongs us! \\
\hline \multicolumn{2}{|l|}{ Description } \\
\hline Emotion words & Horrible/disgusting/your pathetic comment \\
\hline $\begin{array}{l}\text { Verbal descriptions/ascriptions of emotional } \\
\text { states }\end{array}$ & all you can do is whine and point fingers \\
\hline
\end{tabular}

Table 7. Emotional display in the online corpus according to emotional display category and article.

\begin{tabular}{lrrrrrrrr}
\hline Category & Total & $\%$ & $\begin{array}{r}\text { False } \\
\text { Rape }\end{array}$ & $\begin{array}{r}\text { Census } \\
\text { Police }\end{array}$ & $\begin{array}{r}\text { Royal } \\
\text { Wedding }\end{array}$ & $\begin{array}{r}\text { Stricken } \\
\text { Nuclear Plant }\end{array}$ & $\begin{array}{r}\text { Adult movie } \\
\text { teacher }\end{array}$ & $\begin{array}{r}\text { BP market } \\
\text { plunge }\end{array}$ \\
\hline Implication & 176 & 57 & 31 & 26 & 31 & 30 & 24 & 34 \\
Expression & 101 & 33 & 15 & 20 & 26 & 7 & 17 & 16 \\
Description & 32 & 10 & 11 & 1 & 9 & 40 & 4 & 4 \\
Total & 309 & & 57 & 47 & 66 & 13 & 45 & 54 \\
$\%$ & & & 18 & 15 & 21 & & & 15 \\
\hline
\end{tabular}

posts in Table 8. We end up with 378 emotional cues, i.e. more than the previous total of 309 emotional displays, since the overall strategy of implying, expressing and describing could be realized in more than one way within a post. Comparing the frequency of the emotional display strategies in their normalized form in the different argumentative moves of disagreement and extension, we see that there is no difference to speak of between implying emotions (1.3-1.5) and describing emotions (0.2-0.3). Only in the case of expressing emotions, we find a wider range and a larger numerical difference in that agreements contained more of this strategy (1.1) than disagreements (0.8) or extension (0.5). Looking at the overall frequency of emotional indexing (the first two columns), it is striking that we find 3.2 displays of emotional stance per post. Describing emotions occurred in $30 \%$ only, while it is likely that the other two strategies occur in each post. Emotional indexing is thus far from rare and seems to play a vital role in communication. Given the quantitatively attestable presence of emotional display, it is therefore sound to further scrutinize their functionality for the expression of disagreement and the construction of relational meaning in qualitative terms. On the basis of this descriptive statistics, we can therefore return to the interactional dynamics of the online commentaries 
and analyze the relationship between emotions, relational meaning, disagreements and conflict.

\section{Link between emotional display, disagreement and relational work}

Putting our picture together, we claim that the relationship between disagreements, relational meaning, and emotional display can only be appropriately theorized if one regards the overall meaning of disagreements as a complex reciprocal relationship between their conceptual content, relational meaning, and emotional evaluations (see Fig. 3). We regard these dimensions as being reciprocal because all of them can have a direct impact on the other and therefore cannot be separated when defining the notion of 'disagreement'.

Table 8. The implied indexing of emotions, the direct expression of emotions and the description of emotions in the corpus according to argumentative moves.

\begin{tabular}{|c|c|c|c|c|c|c|c|c|}
\hline & Total & $\begin{array}{r}\text { Ratio per } \\
\text { post } \\
\text { overall } \\
(n=120)\end{array}$ & $\begin{array}{r}\text { In } \\
\text { disagree- } \\
\text { ment }\end{array}$ & $\begin{array}{r}\text { Ratio per } \\
\text { disagree- } \\
\text { ment post } \\
(n=104)\end{array}$ & $\begin{array}{r}\text { In } \\
\text { agree- } \\
\text { ment }\end{array}$ & $\begin{array}{r}\text { Ratio per } \\
\text { agreement } \\
\text { post }(n=19)\end{array}$ & $\begin{array}{r}\text { In } \\
\text { extension }\end{array}$ & $\begin{array}{r}\text { Ratio per } \\
\text { extension } \\
\text { post }(n=28)\end{array}$ \\
\hline \multicolumn{9}{|l|}{$\begin{array}{l}\text { Means of implying } \\
\text { emotions }\end{array}$} \\
\hline Conceptual implications & 90 & 0.8 & 63 & 0.6 & 11 & 0.6 & 16 & 0.6 \\
\hline Lexical connotations & 75 & 0.6 & 49 & 0.5 & 9 & 0.5 & 17 & 0.6 \\
\hline $\begin{array}{l}\text { Metaphors and their } \\
\text { stylistic implications }\end{array}$ & 30 & 0.3 & 23 & 0.2 & 4 & 0.2 & 3 & 0.1 \\
\hline Sarcasm & 13 & 0.1 & 9 & 0.1 & 0 & 0 & 4 & 0.1 \\
\hline Irony & 12 & 0.1 & 9 & 0.1 & 0 & 0 & 3 & 0.1 \\
\hline Word play & 3 & 0 & 3 & 0 & 0 & 0 & 0 & 0 \\
\hline Total & 223 & 1.9 & 156 & 1.5 & 24 & 1.3 & 43 & 1.5 \\
\hline \multicolumn{9}{|l|}{ Means of expressing emotions } \\
\hline Exclamations & 41 & 0.3 & 28 & 0.3 & 8 & 0.4 & 5 & 0.2 \\
\hline Intensification & 35 & 0.3 & 24 & 0.2 & 6 & 0.3 & 5 & 0.2 \\
\hline Name calling & 17 & 0.1 & 13 & 0.1 & 1 & 0.1 & 3 & 0.1 \\
\hline $\begin{array}{l}\text { Verbalization of } \\
\text { emotional Reaction }\end{array}$ & 17 & 0.1 & 11 & 0.1 & 5 & 0.3 & 1 & 0 \\
\hline Smileys & 2 & 0 & 2 & 0 & & 0 & 0 & 0 \\
\hline Interjections & 2 & 0 & 1 & 0 & 1 & 0.1 & 0 & 0 \\
\hline Emotional construction & 1 & 0 & 1 & 0 & & 0 & 0 & 0 \\
\hline Total & 115 & 1 & 80 & 0.8 & 21 & 1.1 & 14 & 0.5 \\
\hline \multicolumn{9}{|l|}{ Means of describing emotions } \\
\hline $\begin{array}{l}\text { Verbal } \\
\text { descriptions/ascriptions } \\
\text { of emotional states }\end{array}$ & 30 & 0.3 & 20 & 0.2 & 3 & 0.2 & 7 & 0.3 \\
\hline Emotion words & 10 & 0.1 & 8 & 0.1 & 1 & 0.1 & 1 & 0 \\
\hline Total & 40 & 0.3 & 28 & 0.3 & 4 & 0.2 & 8 & 0.3 \\
\hline Overall total and ratio & 378 & 3.2 & 264 & 2.5 & 49 & 2.6 & 65 & 2.2 \\
\hline
\end{tabular}




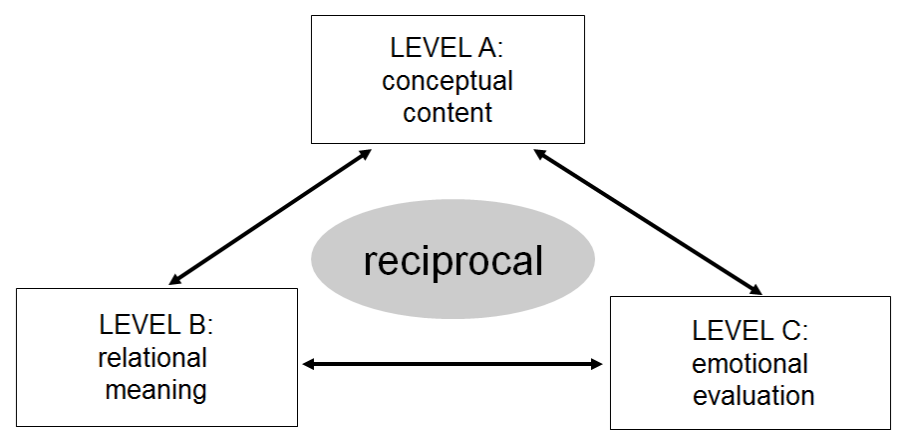

Fig. 3. Construing the meaning of disagreements: 3 interacting dimensions.

To elaborate on this theoretical claim, let us now turn back to and analyze our initial data qualitatively. In line with our proposal, we suggest to scrutinize the discursive dynamics of disagreement and its impact for relational work by dissecting the interaction between the conceptual content, the relational positionality, as well as the evaluative components in each posting. For the latter we rely on our overview of alternative forms of indexing emotions online, i.e. we suggest scrutinizing each disagreement with regard to the specific ways in which emotions are explicitly displayed, described or conveyed through conceptual implicatures. This makes it possible to discuss the type and the intensity of the emotional evaluation that is signaled by the given disagreement.

The first comment by Matt, here reproduced as (1a), addresses the central protagonists in the newspaper article and establishes BP and the UK as the central butts of the poster's disagreement. The contribution presents some propositions about the further treatment of BP by the US and characterizes the UK as a small island that should pay - be it literally or

Disagreement with protagonists in the world of the article

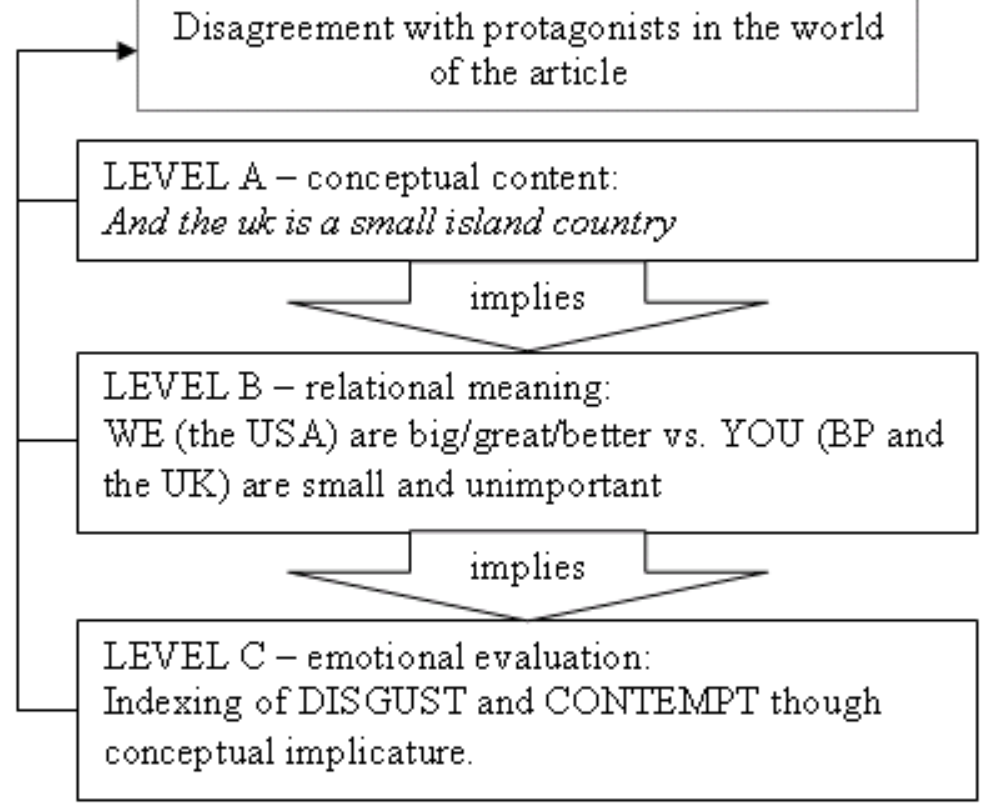

Fig. 4. Emotional evaluation through conceptual implications in Matt's posting. 
metaphorically - for the oil spill catastrophe. For sake of easier discussion, we present this conceptual content in the posting in italics. On the relational plane Matt's comment construes an "US", the USA, vs. THEM, BP and the UK, relationship. The corresponding relational cues in the posting are underlined.

(1a) The US Senate should make the little island called the uk pay for this.

We should just impose our sanctions and will on $\underline{\mathrm{BP}}$. They need us more than we need them. And the uk is a small island country.

As analyzed in section 2.2, on the conceptual level A, the statement "And the uk is a small island country" establishes social distance and imposes an attack against BP and Great Britain, which is portrayed as a protecting and supporting ally of this company. This characterization indexes an underlying emotional evaluation of contempt against UK citizens, which is alluded to conceptually. In terms of the interaction between the three levels of meaning in disagreements, this can be illustrated in Fig. 4.

Matt's claim is fiercely contested by $\mathrm{G}$ from London (2a). This extract is now marked by explicit emotional displays such as the interjection $O h$ yeah and the metaphorical idiom up s@:*s creek. In the passage these emotional cues are marked in bold type.

(2a) Matt, if we pulled out of Iraq, where exactly would that leave the USA? Oh yeah, up S@:*s creek. There may be more american soldiers out there, but there are pleant of British special op's out there clearing the way for the american soldiers. All so you yankies can have cheaper oil... [...]

- G, London, UK, 1/6/2010 21:01

What impact does this display have on his disagreement? In line with our claim, we would like to argue that the emotional signals interact with the conceptual content and the acts of social positioning that is evoked through G's reply. They recontextualize the propositions made by the commentator and clearly indicate G's evaluative stance towards them. $G$ first attacks Matt's construal of the UK as being insignificant in terms of the rhetorical question which implies the ' $W E$ ' cannot be small. However, this rhetorical question is followed by the interjection oh yeah. This evaluative signal seems to imply that the speaker has belatedly realized - with some surprise - that the USA is in a very difficult situation. It must be read as a highly ironic if not sarcastic move. In combination with the informal and negatively connotated metaphorical idiom up shit creek, it points to the irrelevance and absurdity of Matt's claim and thus evaluates it very negatively. G clearly intensifies the display of his annoyance and recontextualizes his previous rhetorical question by expressing his angry and contemptuous stance. On the relational level, G's posting increases the aggressive force that is directed against Matt's face. This relational and emotional aggravation becomes most obvious in the sentence All so you yankies can have cheaper oil. This statement reflects a complex combination of conceptual argumentation, relational work and emotional display. Most importantly, the direct name-calling gesture you yankies combines an act of social positioning 
with negative emotional cues. In the extract this combination is signaled by underlining and bold type. The pronoun you explicitly

highlights the butt of G's attack, whereas the here derogatory social label yankies conveys great amount of negative connotations and conveys an overt and intensive display of annoyance and $\downarrow$ contempt. The combined address term you yankies thus frames G's disagreement with US geopolitical preeminence and military control as an emotionally-charged face attack against Americans in general and Matt in particular.

Emotional contagion becomes obvious in Alicia's reply to G's counter-challenge. What is striking here is the massive increase in explicit and very intensive emotional display and the fact that the conceptual content on which the argumentation is based moves to the background.

(3a) REPLY TO: G, London, UK, 01/6/2010 20:01

All i need to say to your pathetic comment is ...EVERYONE should be out of Afghanistan...and god forbid anything every happened in the UK....who'd be there to back you!?!? Oh...THE US!!!!!!!!!!!! And nature is going to be devestated by this horrible event and all you can do is whine and point fingers... why dont you stop typing and donate hair?? That wont cost your UK anything...selfish lot

- Alicia, USA, 1/6/2010 21:45

Alicia evaluates G's previous statement in the form of the metacomment: "All i need to say to your pathetic comment is...". The emotion adjective pathetic expresses Alicia's feelings of contempt towards G's posting very explicitly and aggressively. Interestingly, she takes up G's argumentative strategy of countering the previous comments by means of a rhetorical question. In her posting, however, the rhetorical question incorporates a great number of intensifying emotional cues that point to its evaluative rather than persuasive force: "EVERYONE, god forbid, !?!? Oh...THE US!!!!!!!!!!!!". On the relational level, she further ascribes weak emotions and selfishness to G: "all you can do is whine and point fingers". Moreover, she fuels the heat of direct face-attack against $\mathrm{G}$ by sarcastically suggesting "why dont you stop typing and donate hair??". Apart from characterizing G's comment as being irrelevant by questioning his writing competence, on the conceptual level this statement implies that G, and his UK compatriots, are poor and ruined and have nothing left to offer the world than their own hair. Note that, metaphorically, the act of donating hair leads to disfiguration and thus implies the loss of (a pretty) face in imaginative but direct terms.

Alicia's aggression against $G$ ends in calling him and the UK selfish lot. Using the adjective selfish, the poster ascribes highly-negatively connoted motives to G's posting. The lexical choice lot is also emotionally charged. The word evokes associations with a mob-like, amorphous, and uncultivated mass of people. In combination with selfish this word triggers a highly unfavorable social categorization of Alicia's butt of disagreement. Alicia thus shifts the conceptual content of her disagreement to the background and performs a frontal face-attack against $\mathrm{G}$ and his compatriots to destroy their argumentative grounds and social positions, respectively. 
The qualitative analysis of the conflict dynamics underlying (1)-(3) substantiates our claim that conceptual content, relational meaning, and emotional evaluation cannot be separated in the interpretation of online disagreements. Rather, the interlocutors' increasingly negative and intense emotional display fuels their heated exchange of positions and causes them to move from competition to confrontation. The corresponding shift away from concept-based and persuasive argumentation towards more aggressive disagreements that are centered on face aggravation is associated with an intensification of both the quantity and the quality of emotional signals that index increasingly negative evaluations of the other and his/her behavior.

\section{Conclusion and further research}

Emotions provide an embodied, internalized value system that guides our processes of sense-making. When interacting in the commentary section of an online newspaper, the emotional expression of the commentator's evaluative stance is therefore vital for signaling his/her orientation to this socio-communicative world of experience. In asynchronous online newspaper comments, language-based signaling becomes the most important tool to establish one's world views and arguments as well as to communicate one's social position. The same is true for displaying emotions. Online disagreements therefore constitute a particularly interesting and relevant testing ground to explore the contribution of a variety of forms of indexing emotional stance.

In this paper we investigated disagreement data taken from the commentary section of the MailOnline, scrutinized the types of emotional display in there, and explored the complex links between emotional display, disagreement and relational work. Our quantitative analysis of 120 English postings from the MailOnline has revealed the notable presence of emotional stance through the display strategies of conceptual implication, explicit expression, and emotional description. While this quantitative survey can neither be regarded as comprehensive nor conclusive, we consider it as a first step towards detecting and coding alternative forms of emotional display in online and other linguistic data. However, a quantitative survey alone is not able to account for the complex communicative dynamics of disagreement and conflict, the relational work that is performed through these acts and the role of emotional display for their appropriate

interpretation. Our brief qualitative analysis of three conflicted postings shows that the interaction between conceptual, relational and affective meaning is both complex and dynamic. This speaks for a discursive approach for studying emotional indexes in conflict and disagreements. We suggest that this is taken as a starting point to further explore the interface of emotions, disagreements, relational work and online communication.

\section{Acknowledgments}

We would like to thank the two external reviewers and Jo Angouri for their helpful and insightful comments. 


\section{References}

Angouri, Jo., 2012. Managing disagreement in problem solving meeting talk. Journal of Pragmatics 44 (12), 1565-1579 Special issue on Theorising disagreement.

Baym, Nancy, 1996. Agreements and disagreements in a computer-mediated discussion. Research on Language and Social Interaction 29, 315-345.

Bolander, Brook, 2012. Disagreements and agreements in personal/diary blogs: A closer look at responsiveness. Journal of Pragmatics 44 (12), 1607-1622 special issue on Theorising disagreement.

Brown, Penelope, Levinson, Stephen C., 1978. Universals in language usage: politeness phenomena. In: Goody, Esther N. (Ed.), Questions and Politeness. Cambridge University Press, Cambridge, pp. 56-289.

Brown, Penelope, Levinson, Stephen C., 1987. Politeness. Some Universals in Language Usage. Cambridge University Press, Cambridge.

Clark, Herbert, 1996. Using Language. Cambridge University Press, Cambridge.

Culpeper, Jonathan, 2010. Impoliteness. Using Language to Cause Offence. Cambridge University Press, Cambridge.

Ess, Charles and the AolR ethics working committee, 2002. Ethical decision-making and Internet research: Recommendations from the AolR ethics working committee. Approved by AolR, November 27, 2002. Retrieved May 22, 2011, from www.aoir.org/reports/ethics.pdf.

Fiehler, Reinhard, 2002. How to do emotions with words: Emotionality in conversations. In: Fussell, Susan R. (Ed.), The Verbal Communication of Emotions: Interdisciplinary Perspectives. Lawrence Erlbaum, Mahwah, New Jersey, pp. 79-106.

Glasl, Friedrich, 1992. Konfliktmanagement: ein Handbuch zur Diagnose und Behandlung von Konflikten für Organisationen und ihre Berater. Paul Haupt, Bern.

Goffman, Ervin (Ed.), 1967. Interaction Ritual: Essays on Face-to-face Behavior. Anchor Books, Garden City, NY.

Grice, Paul H., 1989. Studies in the Way of Words. Harvard University Press, Cambridge, M.A.

Grimshaw, Allan D., 1990. Introduction. In: Grimshaw, Allen D. (Ed.), Conflict Talk. Sociolinguistic Investigations of Arguments in Conversations. Cambridge University Press, Cambridge, pp. 1-21.

Guerrero, Laura K., La Valley, Angela G., 2006. Conflict, emotion, and communication. In: Oetzel, J.G., Ting-Toomey, S. (Eds.), The SAGE Handbook of Conflict Communication: Integrating Theory, Research, and Practice. Sage, Thousand Oaks, pp. 69-96.

Haidt, Jonathan, 2003. The moral emotion. In: Davidson, Richard J., Scherer, Klaus R., Blair, David (Eds.), Handbook of Affective Sciences. Oxford University Press, Oxford, pp. 852-870.

Jones, Tricia S., 2001. Emotional communication in conflict: essence and impact. In: Eadie, W.F., Nelson, P.E. (Eds.), The Language of Conflict and Resolution. Sage, Thousand Oaks, pp. 81-104. Jucker, Andreas, 1992. Social Stylistics: Syntactic Variation in British Newspapers. Mouton de Gruyter, Berlin.

Kempf, Wilhelm, 2003. Constructive Conflict Coverage: A Social Psychological Approach. Irena Regener, Berlin.

Labov, William, Fanshel, David, 1977. Therapeutic Discourse. Academic Press, New York. Langlotz, Andreas, 2010. Social cognition. In: Locher, M.A., Graham, S.L. (Eds.), Interpersonal Pragmatics. Mouton, Berlin, pp. 167-202. 
Locher, Miriam A., Graham, Sage L., 2010. Introduction to interpersonal pragmatics. In: Locher, M.A., Graham, S.L. (Eds.), Interpersonal Pragmatics. Mouton, Berlin, pp. 1-13.

Locher, Miriam A., Langlotz, Andreas, 2008. Relational work: At the intersection of cognition, interaction and emotion. Bulletin Suisse de Linguistique Appliquée (VALS-ASLA) 88, 165-191.

Locher, Miriam A., Watts, Richard J., 2005. Politeness theory and relational work. Journal of Politeness Research 1, 9-33.

Mateosian, Gregory, 2005. Struck by speech. Embodied stance in jurisdictional discourse. Journal of Sociolinguistics 9 (2), 167-193. Muntigl, Peter, Turnbull, William, 1998. Conversational structure and facework in arguing. Journal of Pragmatics 29, 225-256.

Neurauter, Manuela, 2010. Disagreement and impoliteness in online newspapers: personal attacks in reader responses. In: Paper presented at Fifth International Symposium on Politeness, Basel.

Ochs, Elinor, 1992. Indexing gender. In: Duranti, A., Goodwin, C. (Eds.), Rethinking Context: Language as an Interactive Phenomenon. Cambridge University Press, Cambridge, pp. 335-358.

Ochs, Elinor, Schieffelin, Bambi, 1989. Language has a heart. Text 9 (1), 7-25 Special issue: The Pragmatics of Affect.

Pepin, Nicolas (Ed.), 2008. Studies on emotions in social interactions. Special issue of the Bulletin Suisse de Linguistique Appliquée (VALS-ASLA) 88. Neuchâtel: Centre de linguistique appliquée, Université de Neuchâtel. Available at:

http://doc.rero.ch/Im.php?url=1000,20,10,bulletin_vals_asla_2008_088.pdf.

Russell, James A., 1991. In defense of a prototype approach to emotion concepts. Journal of Personality and Social Psychology 60 (1), 117-154.

Schwarz-Friesel, Monika, 2007. Sprache und Emotion. Francke, Tübingen.

Sifianou, Maria, 2012. Disagreements, face and politeness. Journal of Pragmatics 44 (12), 1554-1564 special issue on Theorising disagreement.

Smith, Eliot R., Mackie, Diane M., 2000. Social Psychology. Psychology Press, Hove.

Spencer-Oatey, Helen, 2007. Theories of identity and the analysis of face. Journal of Pragmatics 39 (4), 639-656.

Upadhyay, Shiv R., 2010. Identity and impoliteness in computer-mediated reader responses. Journal of Politeness Research 6, 105-127.

Vuchinich, Samuel, 1990. The sequential organization of closing in verbal family conflict. In:

Grimshaw, Allen D. (Ed.), Conflict Talk. Sociolinguistic Investigations of Arguments in

Conversations. Cambridge University Press, Cambridge, pp. 118-138.

Wilce, James E., 2009. Language and Emotion. Cambridge University Press, Cambridge.

Andreas Langlotz works at the Department of English of the University of Lausanne. His research places a strong focus on linguistic creativity such as reflected in figurative uses of language and idioms (Langlotz 2006, Idiomatic Creativity.) His current work is focused on creative social positioning in workplace discourse and computer-mediated communication. The focus is on the interplay of cognitive linguistics and discourse analysis by developing a "socio-cognitive" approach to the study of language in use (cf. Langlotz, 2010).

Miriam A. Locher is Professor of the Linguistics of English at the University of Basel, Switzerland. She has published on politeness and disagreement (e.g., Power and Politeness in Action, Mouton 2004), impoliteness (e.g., Impoliteness in Language, Mouton 2008, co-edited 
with Derek Bousfield), on computer-mediated practices (e.g., Advice Online, 2006, Benjamins; editor of a special issue in the Journal of Politeness Research), Standards and Norms in the English Language (Mouton, 2008, co-edited with Jürg Strässler) and Interpersonal Pragmatics (Mouton, 2010, co-edited with Sage L. Graham). She is currently working on a project on identity construction in facebook and on reflective writing texts by medical students. 